\title{
Formative Research on Acceptability of Pearl Millet in Rural Eastern Kenya - A Pilot Study
}

\author{
Mueni H. Ndiku', Eddy Jara ${ }^{2} \&$ Joan Sabaté ${ }^{2}$ \\ ${ }^{1}$ School of Science and Technology, University of Eastern Africa, Baraton, Kenya \\ ${ }^{2}$ School of Public Health, Loma Linda University, USA \\ Correspondence: Mueni H. Ndiku, School of Science and Technology, University of Eastern Africa, Baraton, PO \\ Box 2500, Eldoret, Kenya. Tel: 1-524-726-404-401. E-mail: hellenndiku@yahoo.com
}

Received: July 3, 2014 Accepted: August 2, 2014 Online Published: August 4, 2014

doi:10.5539/sar.v3n4p1 URL: http://dx.doi.org/10.5539/sar.v3n4p1

The research was financed by Nestlé and Federico Foundations Switzerland

\begin{abstract}
This study explored the acceptability of pearl millet grain in rural Eastern Kenya. Ninety seven households accepted to plant pearl millet. These were the 37 who were part of the study and other 60 who were not part of the study. When requested to barter $2 \mathrm{~kg}$ pearl millet with maize, $33(85 \%)$ out of 39 bartered with maize, $2(5 \%)$ with sorghum, $2(5 \%)$ with chicken and $2(5 \%)$ with money. The average score for skill attainment was $88 \%$ with $92.5 \%$ mothers readily gaining the skill to prepare and incorporate pearl millet into the daily diet of children. Children liked pearl millet when given with a low of $77.8 \%$ and a high of $93.2 \%$. These findings suggest that policies or programs to promote cultivation, bartering, and consumption of pearl millet grain could be well acceptable in rural Eastern Kenya which could add to the nutritional content of local diets.
\end{abstract}

Keywords: pearl millet, Ukambani-region, acceptability, traditional food reintroduction, under-nutrition, under five children, household and Eastern Kenya

\section{Introduction}

\subsection{Undernutrition in Eastern Kenya}

Despite the Millenium Development Goal to halve the proportion of people who suffer from hunger by 2015 (Black et al., 2008), under-nutrition is associated with over half of all deaths of children worldwide (World Bank, 2006). In spite of efforts made to reduce hunger, some 840 million people remain chronically underfed and malnourished children have actually increased from 18.5 million to 32.7 million worldwide (Frison, Smith, Johns, Cherfas, \& Eyzaguirre, 2010). In Kenya, 30 percent of under five years children are stunted, 24 percent are underweight and 6 percent are wasted (Kenya Demographic and Health Survey (KDHS, 2008). Makueni County also faces nutritional challenges with about 20 per cent of children aged 6-59 months moderately underweight and more than one third of children under five stunted i.e about 34\% (Kenya National Bureau of Statistics (KNBS) and United Nations Children's Fund (UNICEF), 2008).

Hunger at the household level in most parts of Makueni County, Kenya is fueled by climatic conditions and agricultural practices (Chotard, Mason, Oliphant, Mebrahtu, \& Hailey, 2010, Pasricha \& Biggs, 2010). The long-term drought conditions and the resulting erosion from the agricultural practices have contributed to a decrease in the regional dietary diversity.

\subsection{Mobilizing Traditional Food Resources}

The International Plant Genetic Resources Institute (IPGRI) framework to mobilize indigenous and traditional food resources to improve community food security is well-suited to address the causes of undernutrition (Johns \& Sthapit, 2004) in areas such as Makueni in Kenya. This framework has been utilized to help revitalize indigenous food systems and promote increased utilization of food biodiversity to improve nutrition and health in several developing regions of the world (Frison et al., 2010). 
As a first step in applying the IPGRI Framework, we identified pearl millet as an ecologically well-suited, nutritionally efficacious, economically viable, and culturally appropriate grain that can be introduced to address childhood under-nutrition in the Ukambani region of Kenya.

\subsection{Appropriateness of Pearl Millet}

\subsubsection{Ecologically Well-suited}

Pearl millet (Pennisetum Glaucum) was domesticated 4,000 years ago from a wild grass of the southern Sahara (National research council, 1996; Robert \& Myers, 2002).As a result of maize introduction in Kenya after independence in the 1960s, maize surpassed pearl millet as the main crop planted in Kenya. Compared to maize, pearl millet has less cultivation costs since it is more drought resistant, better suited to the arid and semi-arid environments found in most parts of Kenya, can be harvested in fewer days, andit is less vulnerable to pests (World Bank, 2006; National Research Council, 1996; Rathi, Kawtra, \& Sehgal, 2005; Baker, 2008; Railey, 2010). Millets were among the earliest food crops in East Africa before the introduction of the nutritionally inferior staples (maize, wheat and rice) that replaced these robust, nutrient-dense, indigenous crops (Raschke \& Cheena, 2007).

\subsubsection{Culturally Appropriate}

Pearl millet, native to the Ukambani region, is closely tied to the Kamba culture and heritage. Until about 50 years ago, pearl millet was of almost immeasurable value to millions of rural people in Eastern and Southern Africa. It was once the only grain cereal available before maize, rice and wheat were introduced to the Kamba people. Pearl millet had special functions in traditional ceremonies and to make the special bread (Kimutu) that could be stored for many days without spoilage for the long distance traders and hunters.

\subsubsection{Nutritionally Efficacious}

Pearl millet is a very nutritious grain. It contains at least 9 percent protein and a good balance of amino acids, more oils and energy than most grains (National Research Council, 1996; Variano-Marston, \& Hoseney, 1980; Rathi et al., 2005). Pearl millet is high in fat, $4 \%$ of which is $\alpha$-linolenic acid. It contains a myriad of beneficial nutrients such as B-complex vitamins including niacin, thiamin, and riboflavin, the essential amino acid methionine, lecithin, and some vitamin E. The seeds are also rich in phytochemicals (Railey, 2011) (Table 1).

Table 1. Nutritive value of pearl millet compared to other cereal grains (100 gms)

\begin{tabular}{lllllll}
\hline & Pearl millet & Maize & Sorghum & Finger millet & Rice & Wheat \\
\hline Energy (kcal) & 361 & 362 & 339 & 328 & 358 & 349 \\
Water & $12.4 \%$ & $20-32 \%$ & $8-16 \%$ & $13 \%$ & - & - \\
CHO & $67.1 \%$ & $68 \%$ & $68-74 \%$ & $72 \%$ & $79.9 \%$ & $74.1 \%$ \\
Protein & $11.6 \%$ & $6-15 \%$ & $8-15 \%$ & $8 \%$ & $6.2 \%$ & $12.3 \%$ \\
Fat & $5.3 \%$ & $5 \%$ & $2-5 \%$ & $1.3 \%$ & $0.6 \%$ & $1.5 \%$ \\
\hline
\end{tabular}

(Hulse et al., 1980). Food and Nutrition Center Tanzania Food Composition Tables, 2007.

\subsubsection{Economically Viable}

Over the decades an increasing number of farmers, have abandoned pearl millet for maize (Nuss \& Tanumihardjo, 2011). This shift can be attributed to the high economic value that has been attached to maize and other staples like rice and wheat (Raschke \& Cheena, 2007). In addition to its human nutritional value, pearl millet has multiple collateral uses. The straw is a valuable livestock feed, building material, and cooking fuel (Consultative Groups on International Agriculture Research (CGIAR), 2011). Pearl millet's economic value is immense. Pearl millet disappearance was fueled by the economic dependence orchestrated by the neocolonial political economic-structure (Raschke \& Cheena, 2007). The costs of this excision of indigenous knowledge and crops is being felt through the increase of epidemics of obesity, diabetics, cardiovascular diseases and various cancers in this region.

\subsection{Role of Household in Acceptability}

In addition to the ecological, nutritional, economic, and cultural considerations; household acceptability of a re-introduced traditional food is a key part of the IPGRI model that thus far is understudied (Johns \& Sthapit, 
2004). While this change of reintroducing maysound very attractive there seems to be a gap. After decades (two generations) of not using pearl millet, the communities in Ukambani may not be inclined to consider it a viable crop. Mothers may have lost the knowledge to process and prepare it as food for their households. Some mothers may not be willing to accept to incorporate pearl millet, as it is unfamiliar to them and their children.

\subsection{Theoretical Foundation of Study}

This paper reports the result of a multi-pronged exploratory study to advance household acceptability of the pearl millet grain in Makueni County in rural Eastern Kenya. The major theoriesguiding the intervention include elements of theSocial Learning Theory (SLT) (i.e., situations, behavioral capacity, self-efficacy) and the Theory of Reasoned Action (TRA) (behavioral intention). The behaviors of interest are children of participating families consuming pearl millet on a regular basis and bartering maize for pearl millet. We used SLT because of its practical application to the process a learner goes through to adopt a new behavior. The intervention strategies used highlight how the home and community group training were key social and physical situations that could influence in the development of attitudes, norms and intentions that relate to using pearl millet in the home and in the broader community (i.e., reciprocal determinism). Consistent with behavioral capability (i.e., skill and knowledge-building), food demonstrations during parent trainings were designed to increase participants' pearl millet preparation skills. To boost self-efficacy the mothers, who were the training participants' practiced pearl millet preparations during the training and at home (Bandura, 1986, 1991; Edberg, 2007). We hypothesized that participants' with high self-efficacy related to pearl millet preparation would: a) encourage more household pearl millet consumption, b) be willing to barter maize with pearl millet; and c) increase their intention to plant pearl millet.

\subsection{Research Questions}

To test acceptability of pearl millet in rural Eastern Kenya, a formative pilot study was conducted to answer the following questions:

a) What are participant's post-training skill level to prepare pearl millet?

b) To what extent do the children in participating households consume pearl millet on a regular basis?

c) How willing were community members to engage in pearl millet bartering at the end of the study?

d) How willing were community members and participants' household members to plant pearl millet at the end of the study?

\section{Research Methods}

\subsection{Study Design}

This paper reports the result of a two phase exploratory study on the household acceptability of the pearl millet grain in Makueni County in rural Eastern Kenya. The two study phases included: The Community Entry and Recruitment Phase and Implementation Phase.

To raise community-wide awareness and to garner support for the project during the Community Entry and Recruitment Phase, the leader of the research team followed the customary local protocol for initiating a community intervention. The research team leader had the opportunity to discuss the benefits of the pearl millet grain and the scope of the research project in the local language (Kamba) at a baraza, a community-wide meeting organized by the area chief.

The implementation phase consisted of trainings and subsequent activities to explore indicators of pearl millet acceptability such as: willingness to plant pearl millet, bartering pearl millet; mothers' post-training pearl millet menu planning and preparation skills, and children's pearl millet taste scores. Four experienced teachers trained the 40 mothers in diverse skills in handling pearl millet and pearl millet cookery. Maternal and child health education was also given during this training session. Mothers were specifically trained on threshing, winnowing, sieving, sorting, grinding and cooking different recipes using pearl millet. Teaching methods included lecture methods, demonstrations, observations and practical classes. All the mothers who were recruited for training accepted to be trained. An attendance sheet was signed by the participants when they came for training.

This attendance record was used to gauge the mother's willingness to be trained. Training of the 40 mothers took place over 2 weeks (a week for each center). Mothers came on alternative days to each center. Classes began at $9 \mathrm{am}$ and ended at $4 \mathrm{pm}$. A skill score sheet was used to assess the level of attainment of the skill of incorporation of pearl millet in their children's diet. 
The research protocol was approved by the Kenya government and the University of Eastern Africa Ethics Committee Board.

\subsection{Participants}

Two villages were chosen randomly from 15 villages in Itetani location, Tulimani division, Mbooni East. These two villages are about $5 \mathrm{~km}$ apart. Members of households with children under 5 years from these two villages were requested to remain behind after the Baranza. Ballot papers were used to choose 40 households from the 53 which remained. The family representative who picked yes was included and if they picked no they were not. The Kithuma village had 23 participants and Weeni village had 17. This was done during the Baraza meeting. A verbal consent was read to the parents and the mother gave consent on behalf of their child (ren). To finalize the enrollment of the mothers (households) we made house to house visitations led by the village elders to confirm the details given during the Baraza day. Out of these visitations 2 families were dropped and replaced because they did not meet the inclusion criteria of having a child under five years. The forty mothers who were selected signed an attendance sheet as a sign of their willingness to be trained. This attendance record was marked for the entire period of the two weeks of training.

\subsection{Data Collection Instruments and Procedures}

After the training was completed participants were supplied with $8 \mathrm{~kg}$ of pearl millet fortnightly for three months. They were encouraged to feed children and other family members on pearl millet products for a period of 3 months. Research assistants visited the participants to see how they were doing and to collect food frequency data during the three months. An 18-point food frequency questionnaire was administered 5 times over the three months period. This was used to capture the level of incorporation of pearl millet into the children's diet and the entire household too. Only one child from each household was selected for the FFQ interviews since children in a household most likely will eat the same food. This region experiences a monotony of meals i.e there is very little variety in their day to day diets. If twins were participants, both were included and only children who had been introduced to complementary feeding were included.

At the end of the three months an exit interview was conducted. During this interview mothers who were participants were asked if they would barter pearl millet with maize. An exit interview questionnaire was used to document this. The same exit interview questionnaire was used to assess who else ate pearl millet apart from the children. During the exit interviews semi-structured questionnaire data form was used to collect data from mothers on pearl millet incorporation into the diet. During these exit interviews mothers were given $2 \mathrm{~kg}$ pearl millet by the lead researcher $(\mathrm{MN})$ in exchange for $2 \mathrm{~kg}$ of maize. This was documented for each mother. Also mothers were asked if they would plant pearl millet if given the grain and this was also documented for all the households.

\subsection{Data Analysis}

Data from the household surveys were analyzed and descriptive statistics performed using Microsoft Excel, 2007. To assess the level of incorporation of pearl millet in the household diets, we calculated the percentage proportion of pearl millet usage in the household meals for children; calculated the percentage of meals for the households that included pearl millet using the household survey; determined the usage of pearl millet as a staple food; computed the percentage of persons using pearl millet in the household. Finally, the exchange of pearl millet and maize and the willingness to plant pearl millet was assessed.

\section{Key Findings/Results}

Forty-seven children under five years were enrolled: 25 (53.2\%) boys, 22 (46.8\%) girls from the 40 households. The average number of children per household was 5 ( 1 min-12 max), average number of adults 3 ( 1 min- 6 max), average number of the elderly 1 ( 0 min-4 max) and average number of the household members 8 ( 3 min-16 max). The average age of the mothers was 31 years $(19 \mathrm{~min}-63 \mathrm{max})$ and the average age for the children was 28.6 months (3 min -60 max) (Table 2). 
Table 2. Household demographics

\begin{tabular}{|c|c|c|c|}
\hline Mothers $\mathrm{n}=40$ & Children $\mathrm{n}=47$ & Boys $=25(53.2 \%)$ & Girls $=22(46.8 \%)$ \\
\hline \multicolumn{4}{|c|}{ Average Number per household } \\
\hline Children & Adults & Elderly & \multirow{2}{*}{$\begin{array}{l}\text { Household members. } 8 \\
\text { ( } 3 \text { min-16 max })\end{array}$} \\
\hline $5(1 \min -12 \max )$ & $3(1 \min -6 \max )$ & $1(0 \min -4 \max )$ & \\
\hline
\end{tabular}

Children liked pearl millet at the first taste as revealed by the data from the food frequency questionnaires with a low of $77.8 \%$ to a high of $93.2 . \%$. Pearl millet was not only consumed by children but the other family members ate it too. These members included mothers (100\%), fathers $(92.1 \%)$, siblings $(86.8 \%)$, grandpa (42.1\%), grandma (78.9\%) and visitors (97.4\%). Pearl millet was mainly fed to the household members $89.5 \%$ with a small percent $10.5 \%$ fed to domestic animals namely cats $(2.6 \%)$ and chicken $(7.9 \%)$. Averagely per week the households ate pearl millet 6 days ( $\min 2$-max 7 days). All the children meals included pearl millet (Table 3 ).

Table 3. Meals of the day that included pearl millet among children under five years in Rural Eastern Kenya

\begin{tabular}{ll}
\hline Meals of the day & Percentage \\
\hline Breakfast & $100.0 \%$ \\
Lunch & $84.2 \%$ \\
Supper & $65.8 \%$ \\
Snacks & $34.2 \%$ \\
\hline
\end{tabular}

All the mothers who were recruited finished the training save one who relocated and could not complete the training. The 39 mothers who completed the training attained a skill attainment score of $88 \%$ with $92.5 \%$ mothers readily gaining the skill to prepare and incorporate pearl millet into the daily diet of children and other household members.

When given $2 \mathrm{~kg}$ of pearl millet by the lead researcher (MN) to exchange for her with maize during the exit interviews, participants bartered as shown in Table 4. The lead researcher exchanged $2 \mathrm{~kg}$ of pearl millet with the participants to be given maize in turn. All the 39 households who participated in the study agreed to plant pearl millet and they signed an agreement form.

Table 4. Bartering of $2 \mathrm{~kg}$ pearl millet with maize by mothers in rural eastern Kenya

\begin{tabular}{ll}
\hline Items & Number $(\%)$ \\
\hline Maize & $33(85 \%)$ \\
Chicken & $2(2 \%)$ \\
Sorghum & $2(2 \%)$ \\
Money & $2(2 \%)$ \\
\hline
\end{tabular}

When asked why they were willing to do this most of them said they had seen that pearl millet had greater value. Some of the values they mentioned included its high nutritious value and the fact that it was more filling than maize. Specifically a respondent described pearl millet as "nice and sweet to use". Another indicated that "pearl millet made us strong then and we want our young generation to be strong especially women who are the producers of the new generation" (Table 5). 
Table 5. Selected examples of significant statements of interviewed persons on pearl millet and related formulated meanings

\begin{tabular}{ll}
\hline Significant Statement & Formulated Meaning \\
\hline Pearl millet is very nutritious, it is good for & Pearl millet is a nutritious and a valuable grain. \\
children and it gives them energy. We found it very & \\
nice and sweet to use. Porridge is one of the best \\
meals from this grain. Kids like it and we are \\
happy.
\end{tabular}

We never used to feel hungry and we never used to Planting pearl millet can improve food security be sick. Once a child eats pearl millet, it takes time to feel hungry. It satisfies all of us. It stays in the stomach longer.

In fact if allowed I can plant this one you have given us for demonstration. We are ready to plant and our husbands have promised to support us. If we are provided with grain, we can plant. We are ready to plant and will put is a top priority

There is a need to go back to our past tradition of planting this plant. We were brought up with pearl millet.

People are more than willing to plant pearl millet if provided with planting seed.

Pearl millet is strongly tied to Kamba people heritage therefore it is a culturally accepted grain.

Maize is infested with weevils, but pearl millet is not. Maize was there, however, millet was the best.

Pearl millet is superior than maize in some aspects like being pest resistant.

During the same exit interviews when asked if they would plant pearl millet if given the grain, all the subjects indicated yes $100 \%$. This level of commitment was demonstrated by one respondent who indicated that "we are ready to plant and will put it a top priority". They all accepted grain for planting in addition to 58 more people who were not in the project. Thirty five of the 58 came to the distribution centers in the company of those who were subjects. The other 23 were given by those who came to the distribution centers.

\section{Discussion}

The high score for skill attainment of $88 \%$ with $92.5 \%$ mothers readily gaining the skill to prepare and incorporate pearl millet into the daily diet of children is confirmed by the high percentage of meals of the day that included pearl millet, and by the number of other foods served with pearl millet for children less than 5 years. This indicates that pearl millet was accepted and incorporated into other meals at household level. The training was essential to this transition and was confirmed as successful by reports that pearl millet was not hard to prepare and to store. The training increased the efficacy of the mothers in preparation, cooking and storage. Wei-Tao Tai (2006) in support of this fact suggests that, if trainees perceive the information as realistic, the more self-efficacy they will generate, the more motivated they are for training, and finally, the more effective training outcomes will be.

Acceptability of pearl millet products at the first taste by children increased from a low of $77.8 \%$ to a high of $93.2 \%$ during the five visits of collection of the food frequency data. This may mean that over the three months only a small number of the 47 children $(6.8 \%)$ had not fully accepted the product.

From the statements made by the interviewees it is evident that the older people know that pearl millet is nutritious and it is superior to maize in many ways. For example they indicated that pearl millet is nutritious, drought and pest resistant.

Pearl millet contains at least 9 percent protein and a good balance of amino acids, more oils and energy than many grains (National Research Council, 1996; Rathi et al., 2005; Variano-Marston \& Hoseney, 1980). Pearl 
millet is a good source of some very important nutrients, including manganese, phosphorus, and magnesium (The World's Healthiest Foods, 2011). It also contains a myriad of beneficial nutrients such as B-complex vitamins including niacin, thiamin, and riboflavin, the essential amino acid methionine, lecithin, and some vitamin E. The seeds are also rich in phytochemicals (Baker, 2008).

The fact that community members were willing to plant pearl millet is a confirmation of the impact of the project at the community level. This is encouraging because it implies that it is possible to re-introduce pearl millet back into these communities.

Fifty eight people who were not part of this pilot study population planted pearl millet. Thirty five came to the distribution centers while 23 were given by their neighbors who were part of the study. This multiplier effect is very encouraging on the impact of the study. Baker (2008) in support of this, states that, pearl millet's successful production is due almost entirely to its short growing season. While millet hay crops mature in 65-70 days, grain varieties mature in 75-90 days. Millet can also be planted when it is too late to plant other crops.

\section{Conclusion}

Results of this pilot study show that pearl millet is acceptable as a consumption cereal in this part of Ukambani region. The results alsosupport that pearl millet can be reintroduced in the region with ease, following common sense steps: 1) Inform decision makers; 2) Educate and train the food producers and preparers; 3) Provide the grain to get them started.

However, it needs to be seen if incorporation of pearl millet will effect a long term improvement in the nutrition profile of children in the area. More research is needed to determine if the willingness to incorporate or reincorporate this "lost crop" can be sustainable and ultimately change agricultural practices in the region. The results of this formative pilot study will be used to inform a larger clinical trial in the Ukambani region.

\section{Conflict of Interest}

The authors declare no conflict of interest

\section{Acknowledgements}

We thank the Nestléand Federico Foundations, Switzerland for funding this project. The field research team for invaluable assistance during data collection. We also appreciate the time given by the mothers who participated in the training (study) and the "teachers" who trained them. We finally thank the 97 households who have planted pearl millet in an effort to reintroduce it back to Ukambani region of Eastern rural Kenya.

\section{References}

Baker, R. D. (2008). Millet Production Guide A-414. Cooperative Extension Service College of Agriculture and Home Economics. Retrieved from http://printfu.org/read/millet-production-221 c.html?f=1qeYpurpn6Wih-SUpOGul6ynh7nY4tHZ3IXA5NjS 6cnp1tTakbHYrpqfkubdkK_Zr56WppHg2ufc0uDCudPgy5eo2KagsIfaiqDjrJymrojd4dncqaWU1cvK46DX 2-fbo9LJ4Z7m2tbblM_TmK-hmqahk9zT3Iev5Q

Bandura, A. (1986). Social foundations of thought and action: A social cognitive theory. Englewood Cliffs, NJ: Prentice Hall.

Bandura, A. (1991). Social cognitive theory of self-regulation. Organizational Behaviour and Human Decision Process, 50, 248-287. http://dx.doi.org/10.1016/0749-5978(91)90022-L

Black, R. E., Allen, L., H., Bhutta, Z. A., Caulfield, L. E., Onis, De, M., \& Ezzati, M. (2008). Maternal and child undernutrition: global and regional exposures and health consequences, 371, 243-260. http://dx.doi.org/10.1016/S0140-6736(07)61690-0

Chotard, S., Mason, J. B., Oliphant, N. P., Mebrahtu, S., \& Hailey, P. (2010). Fluctuations in wasting in vulnerable child populations in Greater Horn of Africa. Food Nutrition Bulletin, 31, S219-33.

CGIAR. (2011). Millets. Retrieved from http://www.cgiar/our-research/crop-factsheets/millet

Edberg, M. (2006). Essentials of Health Behavior Social \& Behavioral Theory in Public Health. Boston: Jones \& Bartllet Publishers (Chapter 5).

Frison, E., Smith, F., Johns, T., Cherfas, J., \& Eyzaguirre, P. Agricultural biodiversity and health: making a difference to hunger and nutrition in the developing world. Agricultural Biodiversity \& Nutrition Document.

Johns, T., \& Sthapit, B. (2004). Biolcultural diversity in the sustainability of developing-country food systems. Food and Nutrition Bulletin, 25(2), 143-155. 
KDHS. (2008/9). Kenya Demographic Health Survey. Nairobi: Central Bureau of Statistics.

KNSS \$ UNICEF. (2008). Monitoring the situation of children and women. Kenya Eastern Province Makueni District: Multiple cluster survey.

National Research Council. (1996). Lost Crops of Africa: Grains. Washington, DC: National Academy Press.

Nuss, T. E., \& Tanumihardjo, A. (2011). Quality protein maize for Africa: Closing the protein Inadequacy gap in vulnerable population. American Society for Nutrition, 2, 217-224.

Pasricha, S., \& Biggs, B. (2010). Undernutrtion among children in South and South-East Asia. Journal of Pediatrics and Child Health, 46, 497-503. http://dx.doi.org/10.1111/j.1440-1754.2010.01839.x

Railey, K. (2011). Whole Grains: Millet (Gramineae/Poaceoe) Retrieved from http://chetday.com/millet.html

Raschke, V., \& Cheena, B. (2007). Colonization, the new world order, and the eradication of traditional food habits in East Africa: historical perspective on the nutrition transisition. Public Health Nutrition, 11(7), 662-674.

Rathi, A., Kawatra, A., \& Sehgal, S. (2005). Influence of Depigmaentation of Pearl Millet (Pennisetum Galaucum) on Sensory Attributes, Nutrient Compoasiton, in Vitro Protein and Starch Digestibility of Pasta. Food Chemistry, 85, 275-280. http://dx.doi.org/10.1016/j.foodchem.2003.06.021

Robert, L., \& Myers. (2002). Pearl millet a new crop option for sandy soils or other moisture-limited conditions. Published by the Jefferson Institute, Columbia. MO, a non-profit research center supporting crop diversification.

The World's healthiest foods. (2011). Retrieved from http://www.whfoods.com/genpage.php?tname=foodspice\&dbid=53

Variano-Marston, E., \& Hoseney, R. C. (1980). Note on mineral content and location in pearl millet. Cereal Chemistry, 57(2), 150-152.

Wei-Tao, T. (2006). Effects of training framing, general self-efficacy and training motivation on trainee's training effectiveness. Personnel Review, 35, 51-65. http://dx.doi.org/10.1108/00483480610636786

World Bank. (2006). Repositioning nutrition as central to development a strategy for large-scale action. The World Bank for reconstruction and development/ The World Bank. $1818 \mathrm{H}$ street, NW Washington, DC. Retrieved

from http://siteresources.worldbank.org/NUTRITION/Resources/281846-1131636806329/Nutritio

\section{Copyrights}

Copyright for this article is retained by the author(s), with first publication rights granted to the journal.

This is an open-access article distributed under the terms and conditions of the Creative Commons Attribution license (http://creativecommons.org/licenses/by/3.0/). 